U.S. Department of Agriculture

Animal \& Plant Health Inspection Service

Wildlife Services

February 2017

Wildlife Damage Management

Technical Series

\title{
Wildlife at Airports
}

Travis L. DeVault

Supervisory Research Wildlife Biologist USDA-APHIS-Wildlife Services National Wildlife Research Center Sandusky, Ohio

Bradley F. Blackwell

Research Wildlife Biologist USDA-APHIS-Wildlife Services National Wildlife Research Center Sandusky, Ohio

\section{Jerrold L. Belant}

Professor of Wildlife Ecology and

Management

Mississippi State University

Mississippi State, Mississippi

Michael J. Begier

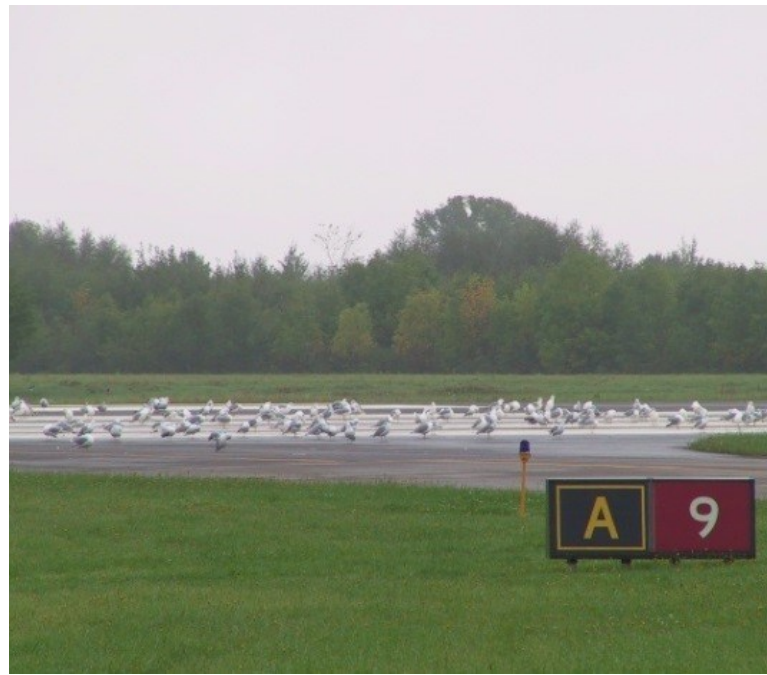

Figure 1. Gulls rest on an airport runway.

National Coordinator

Airport Wildlife Hazards Program

USDA-APHIS-Wildlife Services

Washington, D.C.

\section{Human-Wildlife Conflicts}

Collisions between aircraft and wildlife (wildlife strikes) are common occurrences across the developed world. Wildlife strikes are not only numerous, but also costly. Estimates suggest that wildlife strikes cost the civil aviation industry in the U.S. up to $\$ 625$ million annually, and nearly 500 people have been killed in wildlife strikes worldwide. Most wildlife strikes occur in the airport environment: 72 percent of all strikes occur when the aircraft is $\leq 500 \mathrm{ft}$ (152 $\mathrm{m}$ ) above ground level, and 41 percent of strikes occur when the aircraft is on the ground during landing or takeoff. Thus, management efforts to reduce wildlife hazards are focused at the airport. There are many techniques used to reduce wildlife hazards at airports, and these usually work best when used in an integrative fashion. Here, we discuss the available data on wildlife strikes with aircraft, summarize legal considerations, explain why wildlife are attracted to airports and how to identify important wildlife attractants, describe commonly-used tools and techniques for reducing wildlife hazards at airports, and explain how airports can enlist the help of professional wildlife biologists to manage wildlife hazards. 


\section{Monitoring Wildlife Strikes}

The many techniques and tools used to reduce wildlife hazards at airports have a foundation in applied research. Management is most effective when aided by a thorough understanding of the species involved in strikes and the local habitats that support them. In the U.S., the Federal Aviation Administration (FAA) in conjunction with the U.S. Department of Agriculture (USDA) Wildlife Services program manages the National Wildlife Strike Database, which contains records of strikes between wildlife and aircraft from 1990 to present. Growing knowledge of wildlife strikes with aircraft over the past two decades has formed the basis for research questions, recommendations for management, and the foundation for regulations to address wildlife hazards to aviation.

The National Wildlife Strike Database contains more than 169,856 wildlife strike records (from 1990-2015), including 13,795 reported in 2015 alone. Of those strikes reported in 2015, approximately 5 percent caused damage to the aircraft. Furthermore, wildlife-strike reporting for civil aircraft in the U.S. is not mandatory, and recent analyses suggest that only about 47 percent of such strikes are reported to the FAA. Thus, based on the most recent data available, we can estimate that every day there are, on average, about 38 wildlife strikes with U.S. civil aircraft reported to the FAA, of which about 2 cause damage to the aircraft (Figure 2). Although approximately 97 percent of wildlife strikes are collisions with birds, aircraft strikes with mammals, especially deer (Cervidae), occur frequently and often cause aircraft damage.

Increasingly, more strike information is collected and wildlife remains are identified, often to the species level, at the Smithsonian Institute Feather Identification Laboratory. This type of information can be critical when attempting to mitigate or provide airports with effective management recommendations. Precise knowledge of the birds or other wildlife involved with strike events can lead to more targeted recommendations, especially when it involves habitat alteration. Additionally, as airport wildlife mitigation programs mature, there is a need to evaluate the effectiveness of the program or its components. Diligent collection of strike data makes this possible so that programs can be tracked over time and changes made as necessary.

\section{Legal Considerations}

At the international level, the International Civil Aviation Organization (ICAO) provides global standards and guidance for member nations regarding wildlife hazards to aviation. ICAO mandates that member nations (1) assess hazards posed by birds and mammals in the vicinity of airports certificated for passenger traffic, (2) take all necessary actions to decrease the numbers of hazardous birds and mammals, and (3) eliminate or prevent the establishment of wildlife attractants on or near airports. Another key component of the ICAO guidance is the recommendation that member nations create a committee to assess and respond to wildlife hazard problems at their airports.

To comply with ICAO standards, the FAA mandates that airports in the U.S. initiate formal assessments of wildlife hazards, referred to as Wildlife Hazard Assessments (WHAs), when certain triggering events occur, such as a

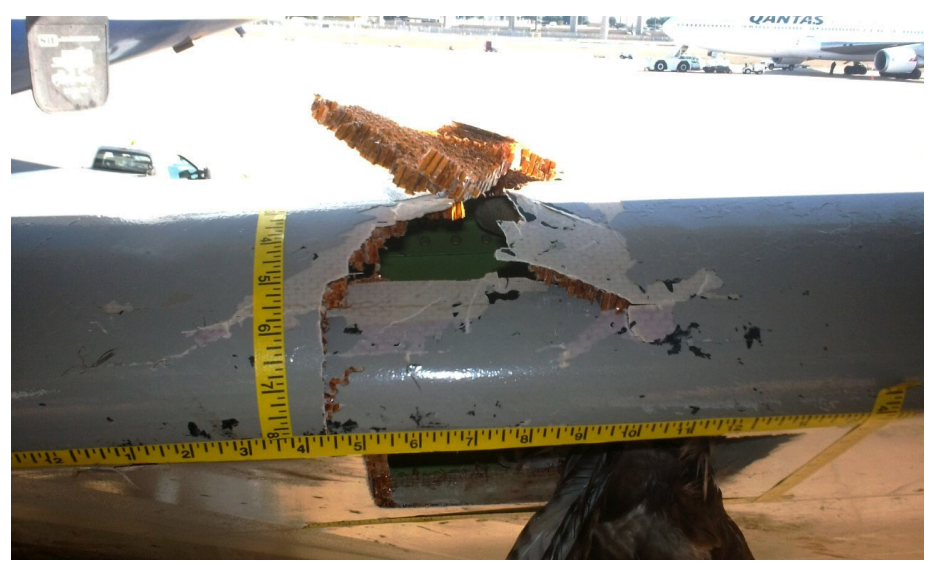

Figure 2. On average, about 38 wild life strikes with U.S. civil aircraft are reported to the Federal Aviation Administration every day. 
damaging wildlife strike. The WHA uses a combination of qualitative and quantitative techniques commonly associated with wildlife management to collect data and assess the impact of wildlife and wildlife attractants on airport safety. Data are primarily collected at the airport, but also outside of the airport within FAA-identified separation criteria related to predominant aircraft use of the facility. This information is then summarized and recommendations are generated that can help the airport alleviate wildlife concerns. The recommendations from the WHA are integrated by the airport into a Wildlife Hazard Management Plan (WHMP) that is used to specify how the airport will approach and implement the recommendations over time. The basics of both the WHA and WHMP are discussed in FAA guidance and regulations via the Federal Code of Regulations (Title 14 CFR Part 139.337), Advisory Circulars (ACs), and Certification Alerts (CertAlerts). A new $A C$ is being developed to provide more detailed standards for conducting WHAs and WHMPs for airports. Minimum qualifications for wildlife biologists providing assistance to airports are the subject of another AC.

When implementing WHMPs, airport personnel must abide by relevant local, state, and federal laws and regulations concerning natural resources and transportation safety. As such, wildlife management at airports is often conducted within a complex legal environment. For example, most bird species in North America are federally protected under the Migratory Bird Treaty Act. But some birds also receive protection from the Endangered Species Act or other regulations. State regulations often parallel federal guidelines and in some cases provide primary oversight. For instance, many game animals, including birds like wild turkeys (Meleagris gallopavo), are regulated at the state level.

One highly regulated activity at the state and federal levels is legal take (lethal removal) of wildlife. At the federal level, recommendations from USDA are required for the application process to obtain a migratory bird depredation permit administered by the Department of Interior (U.S. Fish and Wildlife Service; FWS). Permits are issued with strict guidelines and this process is identified in the Federal Code of Regulations. Data on wildlife use of the

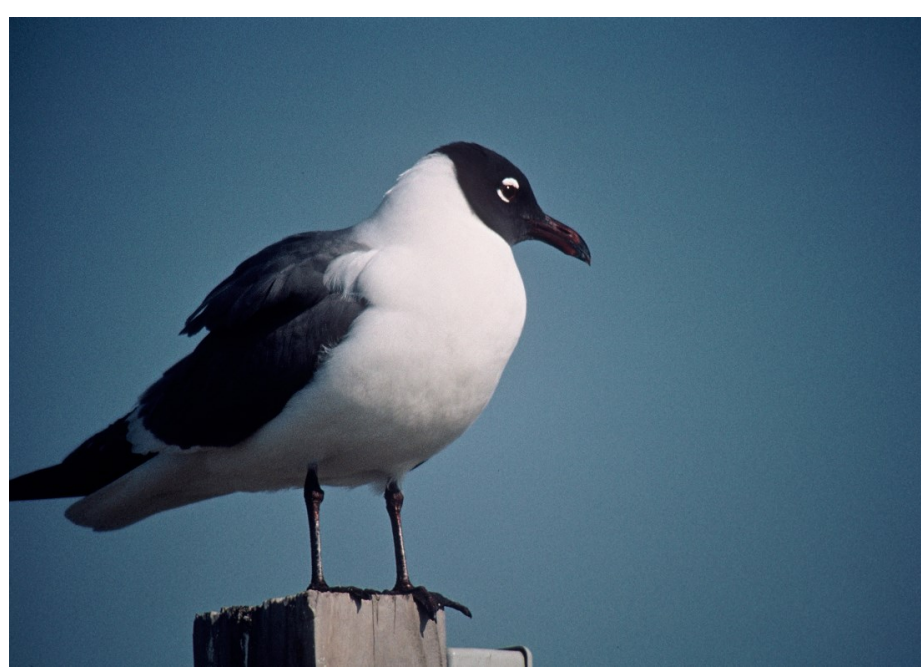

Figure 3. Most bird species in North America are federally protected under the Migratory Bird Treaty Act and their capture or lethal removal requires a permit. When implementing a Wildlife Hazard Management Plan, airport personnel must abide by relevant local, state and federal laws and regulations concerning birds and other natural resources.

airport are required to be documented annually and submitted to the FWS. Bird depredation permits are similarly required at different levels by state governments and similar application procedures exist, but are not uniform. Other state-regulated wildlife (e.g., deer, furbearers, and game birds) are typically managed via special airport depredation permits, depending on the state agency involved. Other broad-based depredation orders exist at the federal level and are used to help manage wildlife populations that may impact airport safety (e.g., resident Canada goose [Branta canadensis], doublecrested cormorant [Phalacrocorax auritus]).

Safety, as a topic and focus area within aviation, is being adapted into a new paradigm, the Safety Management System (SMS). As a process, SMS is dependent on an open safety culture and reliant on quality data to help identify and address safety risks and other concerns. As SMS becomes more prevalent in the airport environment, wildlife hazard data collection will become integrated within a risk-based measurement system. 


\section{Attractants at Airports}

Before wildlife management actions are implemented at an airport, it is important to understand the local wildlife attractants. This information is typically gleaned via the year-long WHA. Here, we focus on the three primary needs of wildlife-food, water, and cover-and relate them to the airport context. Readers are also encouraged to see FAA AC 150/5200-33B, "Hazardous Wildlife Attractants On or Near Airports", which provides guidance for airports in the U.S. on land uses that potentially attract hazardous wildlife.

\section{Food}

Many studies across a wide variety of habitats have shown that food location and availability are primary determinants of wildlife movements and activity patterns. Airports are no exception-although wildlife use airport environments for many reasons, the primary motivation for most individuals is to find food.

Wildlife food resources at airports take many different forms. For example, Canada geese, which are among the most hazardous birds to aircraft, often visit airports to feed on turfgrasses planted alongside runways and taxiways. Gulls (Laridae) and European starlings (Sturnus vulgaris) feed on insects in airport grasslands, as well as earthworms that come to the surface following heavy rain. Raptors (e.g., hawks [Accipitriformes] and owls [Strigiformes]) use airport grasslands and weedy areas to hunt for voles and other small mammals (Figure 4). Airport trash and food waste, when not carefully managed, can attract birds such as gulls, rock pigeons (Columba livia), starlings, and other species closely associated with humans. Seeds and fruits produced by airport landscaping plants and naturally-occurring trees and shrubs can attract many types of birds. Also, some agricultural practices, especially the production of corn and small grains, are surprisingly common on airport properties and can attract waterfowl, gulls, deer, and other hazardous species during certain times of the year.
Because wildlife food resources found at airports are so varied, it is difficult, if not impossible, to remove them completely. Often the most effective and straightforward way to reduce use of airport properties by hazardous birds and mammals, and thus increase aviation safety, is to determine which types of food are being selected and then remove those foods from the airport.

\section{Water}

Surface water, including natural water bodies, poorly drained areas, aquaculture facilities, and exposed stormwater detention/retention facilities often represent a substantial portion of the area within FAA siting criteria for certificated U.S. airports (i.e., surface water within $1.5 \mathrm{~km}$ of a runway for airports servicing piston-powered aircraft and within $3.0 \mathrm{~km}$ of a runway for airports servicing turbine -powered aircraft). All of these water resources on and near airports can serve as attractants to wildlife and pose hazards to aviation safety. Unfortunately, the management of water resources intended to achieve water quality goals and provide safe operating surfaces for aircraft is often at odds with management intended to minimize attractants to birds and other wildlife. Thus, effective water management on and near airports to reduce hazards to aviation depends on collaboration among airport biologists, airport

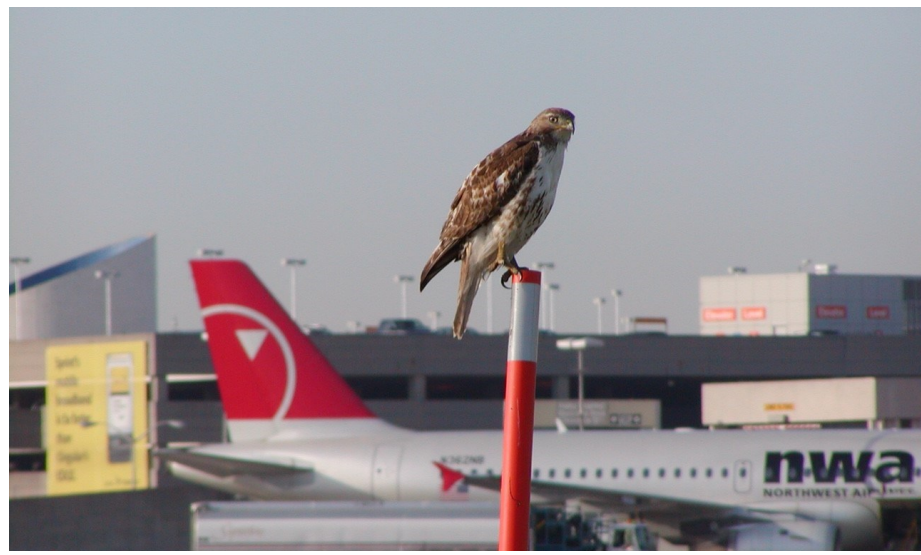

Figure 4. Raptors (e.g., hawks and owls) use airport grasslands and weedy areas to hunt for small rodents and other mammals. 
managers, and engineering personnel to develop bestmanagement practices that meet the complex safety and regulatory requirements facing airport managers.

Aside from regulatory issues, the development of effective management to control wildlife use of water resources requires an understanding of the features of these systems or facilities that serve as attractants. In a broad sense, bird use of water resources is primarily driven by site-specific relationships of system, area, cover, food resources, and habitat complexity with regard to neighboring resources.

For example, wetland area and vegetation cover figure prominently as attractants to birds. Within wetland systems, the number of bird species is generally higher in wetland complexes as opposed to larger, isolated marshes. Also, wetlands with an intermediate level of emergent cover (33-66\%) have been found to host the greatest species richness.

Complete coverage of water bodies (physically and visually) will provide the most effective means of reducing the attraction to birds and limiting access to other wildlife. However, cover alternatives can pose problems because of cost, maintenance, and water-quality issues, and thus are not always feasible. When water resources cannot be drawn down in an effective and timely manner (e.g., within 48 hours of a storm event) or completely covered and drawn down at a later date, managers should consider integrating netting and harassment. In addition, we suggest that airport managers and airport biologists consider new advances in Subsurface-flow Wetlands and Low-impact Development/Green Infrastructure methods. These methods provide means of reducing peak flow of stormwater, enhancing infiltration and contaminant removal, as well as reducing standing water and volume of runoff that must be contained, thereby reducing wildlife use.

\section{Cover}

In addition to food and water, the third basic element for wildlife is cover. Cover (or shelter) is integral to sustained wildlife use of an area and is important to many behaviors including roosting, nesting, denning, hiding or escape, and foraging. Minimizing the amount and availability of cover in airport environments is critical for reducing overall suitability for wildlife and should be an important component in wildlife management plans at airports. Understanding the cover requirements of wildlife species, particularly those most hazardous to aircraft, will aid in developing strategies to reduce wildlife cover.

For reasons including visibility, safety, and risk management, the composition of land covers at airports is predominantly herbaceous grasses and forbs, collectively referred to as grasslands. Additional land covers include developed areas such as airport terminals, parking garages, hangars, and runways; and occasionally forest patches and open water or wetland areas. Trees, shrubs, and wildflowers used as landscaping around buildings and parking areas can also serve as wildlife cover.

Virtually any land cover will serve as cover for some wildlife species. The amount and location of these land covers will also influence wildlife use. How landscaping and buildings are designed and maintained can markedly influence the attractiveness of an airport to wildlife. For example, areas with tall grasslands can provide resting sites for deer. Tall grassland areas can also provide cover for small mammals, which in turn could be preyed upon by hazardous wildlife including raptors and coyotes (Canis latrans). Trees and forest patches often provide roosting and nesting sites for birds; if large enough, the associated understory vegetation of forest patches can provide hiding and escape cover for wildlife. Pigeons, starlings, and other small flocking birds may also use hangars and parking garages for roosting and nesting sites.

Relative suitability of land covers may also vary seasonally. Wildlife use of grasslands and forest patches may be reduced during winter when plants age, go dormant or drop their leaves. This in turn, could increase the relative suitability of other land covers, such as bird use of buildings for roosting or thermal cover. Wildlife cover cannot be eliminated completely at airports, but can be reduced through effective planning and management informed by an understanding of species ecology. 


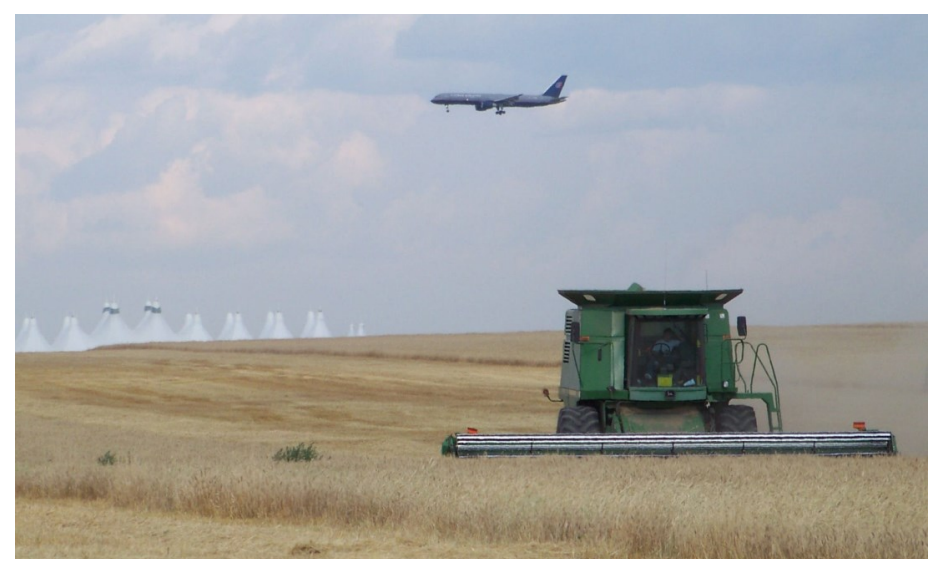

Figure 5. Some airports, particularly general aviation airports, plant agricultural crops within or immediately adjacent to airport property. Although planting crops can generate revenue, many agricultural crops are attractants to hazardous wildlife and not recommended.

\section{Management Methods}

Here we discuss some of the primary methods and tools used for managing wildlife on and near airports. Irrespective of the target species and the airport, it is important that management techniques are used in an integrated way-no single method or technique will sufficiently mitigate all wildlife hazards to aviation. Also, it is important that management is prioritized to minimize strike risk for the most hazardous species that are commonly found at the airport (i.e., those most likely to cause aircraft damage when struck). Strike risk is not simply the identification of a potential hazard, but an assessment of the realistic potential for damage associated with wildlife strikes. Thus, management of airport habitats and wildlife populations on and near an airport go hand-in-hand with reducing the overall probability of strikes, the associated safety issues, and direct and indirect costs to the airline and airport.

\section{Habitat Modification}

Unlike other areas of wildlife management, habitat modification at airports involves changing the physical environment to reduce its suitability or attractiveness to hazardous wildlife species. Although likely not a linear relationship, any management action that reduces or eliminates food, water, or cover should reduce associated use by wildlife. Though initial costs of habitat modifications can be high compared to other techniques, the associated benefits of long-term reductions in wildlife use can result in net savings to airports. Thus, it is important to consider wildlife habitat modifications during all planning phases of airport construction or renovation.

Grasslands are the dominant land cover at most airports. Recommended herbaceous ground cover height to reduce wildlife use varies markedly among organizations and agencies. Recommended heights are typically from 6 to 14 inches $(15-36 \mathrm{~cm})$; however, there is little scientific evidence to suggest this is an appropriate height range to reduce wildlife use. We suggest biologists consider the most common hazardous species present at the airport that use these areas and adapt mowing regimens accordingly. For example, if large flocks of smaller birds (e.g., European starlings) are of concern, maintaining taller grass heights could obstruct their visibility and reduce use. However, tall grass can harbor greater numbers of insects, which could increase foraging success and use by starlings. In addition, tall grass might contribute to increased small mammal and rabbit abundance, important foods for coyotes and raptors. As multiple hazardous wildlife species can potentially occur at most airports, assessing the relative risk of each hazardous species is often necessary to determine the most effective habitat modifications.

As with grass height, the density of vegetation and the amount of bare ground in grassland areas can also influence food (e.g., insects and earthworms) abundance and availability. This in turn can affect wildlife use of these areas. Knowing the diets and optimal foraging conditions of hazardous species will help managers determine the most appropriate management actions, whether modifying mowing regimens, applying insecticides, or adding fertilizer to increase plant density.

Plant species composition can also be very important. We recommend using plant species of low nutritional quality or palatability whenever possible. For example, zoysiagrass (Zoysia japonica), centipedegrass (Eremochloa ophiuroides), and St. Augustinegrass (Stenotaphrum secundatum) are not preferred as forage by Canada geese 
and should be considered when reseeding or replanting areas at airports. In contrast, Kentucky bluegrass (Poa pratensis) and fine fescues (Festuca spp.) are preferred forage for geese and not typically recommended for use at airports.

Some airports, particularly general aviation airports, plant agricultural crops within or immediately adjacent to airport property. Although planting crops can generate revenue, many agricultural crops are attractants to hazardous wildlife and not recommended (Figure 5). The costs of control efforts and potential wildlife strikes should be considered against the economic benefits of planting crops when deciding whether to allow crops on airport property.

Landscaping at airports should be done with caution as many plants or other landscape structures can serve as wildlife attractants. Trees and shrubs that produce fruits should be avoided, as they can attract birds when fruit are mature. Trees and shrubs can also serve as roosting sites and escape cover for wildlife. We recommend using trees and shrubs sparingly in landscaping. In addition, other woody cover at airports is attractive to many wildlife species and, in general, should be removed. If complete tree and shrub removal is not a viable option, reducing their numbers or thinning the crowns may reduce their suitability as roosting and nesting sites.

Water, as noted earlier, is a major attractant for birds and mammals at airports and should be eliminated or made inaccessible to wildlife as much as possible. For example, it may be possible to eliminate stormwater runoff through the construction of underground retention systems. Planting emergent vegetation in open water areas has been used in efforts to reduce bird use. However, there currently is no candidate vegetation that minimizes available water surface area for birds, survives both flooding and water draw down, and denies food, roosting, or nesting opportunities. Thus, when open water areas including ponds and ditches cannot be eliminated, complete coverage of these areas using synthetic or floating covers is recommended.

Other habitat modifications include the use of alternative land covers, such as herbaceous biofuel stocks for hay or biofuel production. Preliminary research suggests the risk to aircraft from wildlife use is no greater than traditional herbaceous land covers and may also provide revenue and environmental benefits including carbon sequestration and conservation value to non-hazardous grassland bird species. However, additional research is necessary to determine which biofuel stocks are most appropriate for use at airports. Alternative energy production, particularly solar energy, is a habitat modification that can reduce wildlife use on airports and result in substantial energy cost savings to airports. Photovoltaic solar arrays have been established at several U.S. airports with no reported increased risk from wildlife use. However, hazardous birds may use solar panels for perches and shade.

Habitat modifications are often difficult to implement and typically expensive. Furthermore, habitat management varies regionally and depends upon the wildlife species present and existing land covers within and in close proximity to the airport. By determining the most hazardous species at the airport and understanding their life history requirements, managers can identify the most appropriate and effective habitat management actions.

\section{Fencing}

Although the majority of reported wildlife strikes with aircraft involve birds, strikes with medium- and large-sized mammals like deer and coyotes are much more likely to result in damage to the aircraft. For example, the National Wildlife Strike Database indicates that 59 percent of reported aircraft strikes with mammals (excluding bats [Chiroptera]) caused damage to the aircraft. Because of the relatively high overall hazard level of mammals to aircraft, it is imperative that airports possess and maintain perimeter fences that effectively exclude these animalsespecially deer-from aircraft operating areas.

In CertAlert 04-06, the FAA recommends 10-12-ft (3.053.66-m) chain-link fencing with 3-strand barbed-wire outriggers and a 4 -ft (1.22-m) skirt buried at a $45^{\circ}$ angle to the outside for excluding deer. Even so, the FAA recognizes that other fence types, such as 8-ft (2.44-m) chain link and even shorter electric fences, may be suitable in circumstances where deer activity is low and 
cost or environmental impacts prevent the use of taller fences. The FAA also recommends that gates close with no more than 6-in $(15-\mathrm{cm})$ gaps and that fence lines are checked daily for breaches (e.g., gaps, holes, washouts) that could allow entry by mammals hazardous to aircraft.

When well-maintained, $\geq 10$-ft (3.05-m) chain-link fencing is extremely effective in excluding hazardous mammals from critical areas and is ideal for airport use (Figure 6).

However, such fencing is expensive, and some general aviation airports, in particular, may need to consider other options. There is a wide variety of fence types available, ranging from temporary polypropylene snow fence to 15 strand electric high-tensile wire. When selecting a fence for use at an airport, managers should consider population sizes of deer and other mammals hazardous to aircraft in the surrounding area, the level of motivation for these animals to breach the fence, surrounding terrain, and cost over the lifespan of the fence. In addition to the fencing itself, it is important that proper gates are chosen for use at airports. Traditional hinged gates may not be practical in some high-traffic areas. Fortunately, several alternatives to traditional hinged gates, including bridge grates, modified cattle guards, and electric mats have been tested for effectiveness in excluding deer and other mammals and are available for airport use.

Regardless of the type of fence and gates used at an airport, it is vital that they are checked regularly and that breaches are repaired as soon as they are discovered. Deer, coyotes, and other mammals hazardous to aircraft will quickly find and use fence gaps and holes. Furthermore, research conducted at the USDA, Wildlife Services, National Wildlife Research Center suggests that white-tailed deer will rarely attempt to jump an 8-ft (2.44$\mathrm{m})$ fence, even when their lives are threatened. Thus, a well-maintained 8-ft (2.44-m) fence is generally more effective at excluding medium- and large-sized mammals from critical airport areas than a neglected 12-ft (3.66-m) fence. However, irrespective of fence height, it is unlikely that any airport fence will be completely mammal-proof. Whenever deer or other mammals hazardous to aircraft are found within airport perimeter fences, they should be removed immediately to eliminate the risk of damaging aircraft strikes.

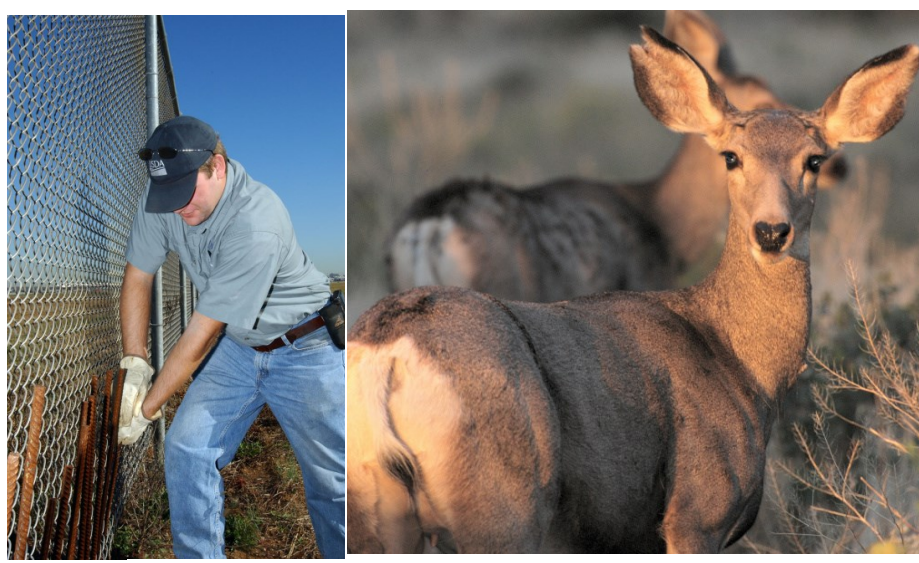

Figure 6. When well-maintained, 10 -foot or higher chain-link fencing is extremely effective in excluding hazardous mammals, such as deer, from critical areas and is ideal for airport use.

\section{Translocation}

Wildlife translocation is a management technique in which individual animals are captured and moved to a new location. Translocation has been used successfully for many years to create hunting and trapping opportunities (i.e., stock game), enhance populations of rare species, and reintroduce extirpated species. In the context of wildlife damage management, animals are captured in a location where they are considered overabundant or otherwise unwanted, and then moved to a location where their presence is less problematic. At airports, translocation is usually limited to raptors, generally large birds that are among the most hazardous to aircraft.

Ostensibly, translocation is an attractive option for managing raptors at airports-the hazard is completely removed from the airport environment without the (immediate) death of the bird. Translocation of raptors is considered more socially acceptable than lethal control, and this technique has been used widely at U.S. airports (Figure 7). For example, from 2008 through 2010, USDA Wildlife Services biologists translocated more than 600 red -tailed hawks (Buteo jamaicensis) from 19 airports.

Although translocation shows promise and likely deserves a place in wildlife management at airports, it is not a universal remedy. Many U.S. states limit the translocation 


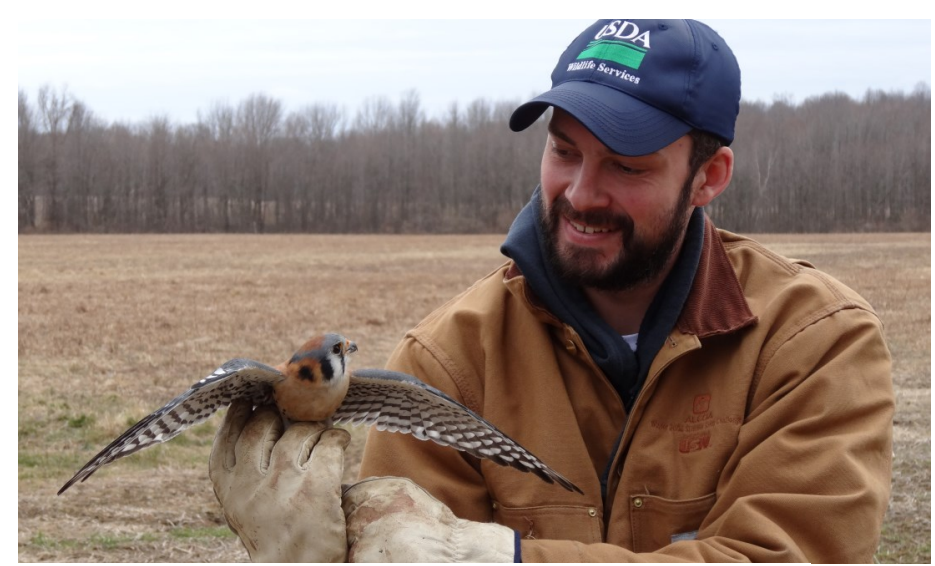

Figure 7. Translocation is a nonlethal option for managing raptors, such as this American kestrel, at airports.

of some species because of the potential to introduce wildlife diseases to new areas. Also, translocation is laborintensive and thus expensive (although costs have not been formally quantified), and relocated raptors sometimes return to the airport where they were captured. Furthermore, survival rates of translocated individuals are not well understood, and it is unclear how translocation affects established animal communities at relocation sites. In general, more research is needed before translocation can be used most effectively at airports.

\section{Visual Deterrents}

Visual deterrents are generally intended to provoke a fear response (e.g., antipredator behavior), and rarely provide effective deterrence when used alone. However, the period of effectiveness can be increased and habituation decreased by considering the sensory and behavioral ecology of the target species, the context of application, and how a particular method might be integrated with other techniques to enhance perception of predation risk.

For example, vision is highly developed and represents the primary sensory pathway in birds. Birds have visual systems that differ substantially from mammals, including greater visual resolution and enhanced color vision (e.g., many birds can see in the ultraviolet range of the electromagnetic spectrum). Therefore, visual deterrents for birds that incorporate color, in addition to movement, should consider the visual capabilities of the target species. Mammals, on the other hand, often rely heavily on olfaction and hearing, and to a lesser extent on vision. However, dogma often suggests limitations to mammalian vision that are inaccurate. For example, white-tailed deer (Odocoileus virginianus) are not color blind, but are "dichromatic", with peak abilities in the blue and green portions of the spectrum. In addition, like other mammals active at night, deer and their relatives can see well in dim light. As with deer, the importance of the visual pathway to canids (dogs and their relatives) varies with the species and context, and some canids can see well in the blue and green portions of the spectrum. We note that there is little evidence that canids respond to color signals. However, movement and novelty have played a role in the effectiveness of deterrents.

In addition to matching the visual deterrent to the biology of the target species, it is also important to understand context. In other words, just because an animal can see the deterrent being used does not necessarily mean it will react in the desired manner. We must ask whether the deterrent has the potential to stimulate instinctive avoidance behaviors, as with some natural signals, or whether the deterrent requires a period of learning accompanied by reinforcement. For example, wood pigeon (Columba palumbus) wing marks can serve as natural visual alarms to other wood pigeons. Although the ecological implications of wood pigeon wing marks seem distant from the use of visual deterrents on airports, the principle is not. The ecological importance of the visual cue that is paired with the deterrent is critical. In other words, is the cue effective for the right reasons. Does it enhance the animal's perception of risk to the resource you want to protect or is the animal associating it with something else? Another example is the use of disruptive visual stimuli (e.g., fladry) against wolves (Canis lupus) that decrease predation on livestock, but do not produce or stimulate an aversion to the resource. One should also consider that a visual deterrent might be detected and considered important because it occurs within the context of a familiar habitat (e.g., coyote response to an intruder's sign or a novel object within the animal's territory). However, if this same coyote encountered a novel object outside its territory, the coyote would likely show little interest 
even though the object is readily detectable, because there is no threat perceived from the cue.

The effectiveness of a visual deterrent that is readily detectable and used within the appropriate ecological context (e.g., deterring foraging or, more broadly, use of a specific area) can be enhanced through the integration of methods. For example, the use of visual barriers against deer (i.e., fences that the deer cannot see through) has recently shown promise for airport or agricultural applications, but only as a method to be integrated with harassment or lethal control, and as a precursor to more permanent deer-proof fencing. Similarly, the use of avian effigies (models of dead birds or taxidermy mounts) as deterrents has proven effective, particularly if integrated with laser dispersal. The use of trained border collies (Canis familiaris) or falconry against birds on airports is common, though their efficacy is debatable from the perspective of long-term, cost-effective deterrence. Finally, a combination of visual obstruction via maintenance of a particular grass height, control of food resources, and harassment recently has been recommended as a dynamic method for managing airport grasslands to deter use by birds. In each scenario, however, deterrent detectability and context contribute to the effectiveness of the visual deterrent, and integration with other methods will enhance efficacy.

\section{Auditory and Tactile Repellents}

Along with vision and smell, auditory (hearing) and tactile (touch) are categories of primary physical receptors in birds and mammals. These receptors can be triggered by repellents and influence animal behavior. Thus, auditory and tactical repellents can be important tools for reducing hazardous wildlife at airports when used within an integrated wildlife management strategy. Auditory repellents can be any device that produces sound in the audible (to most vertebrates; $20 \mathrm{~Hz}-20 \mathrm{kHz}$ ) through the ultrasonic range (some rodents and bats; >20 kHz-200 $\mathrm{MHz}$ ). Tactile repellents can be spikes of various designs, electric shock, tacky or sticky substances, moving or static wires, or chemical compounds designed to create pain or discomfort. Auditory repellents are generally used to disperse birds and mammals from larger open areas

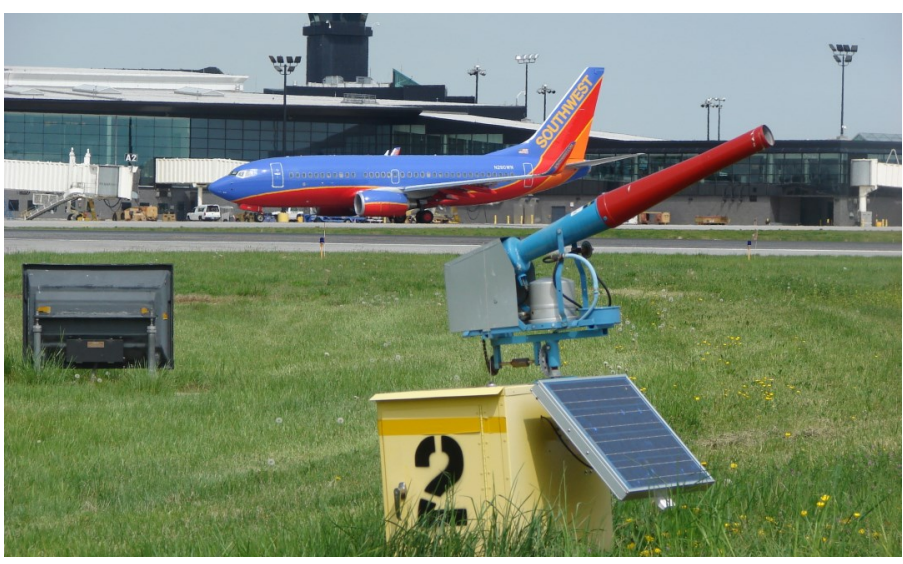

Figure 8. The use of auditory repellents, such as propane exploders or cannons, are part of an integrated approach for reducing wildlife risk. Periodically changing their locations, as well as their frequency and timing of stimuli, can increase their effectiveness.

whereas tactile repellents, depending on type, are more suitable for reducing wildlife use of specific structures.

Like visual deterrents, the sensory ecology of the target species must be considered to maximize efficacy of auditory and tactile repellents. Hearing is influenced by the frequency of the sound as well as the intensity or volume (i.e., sound pressure level). In general, birds hear well within a limited frequency range, but appear to hear less well than humans over a wider range. Birds react most to sounds from 1 to $3 \mathrm{kHz}$, but the hearing range can vary markedly among species, with some birds most sensitive to sounds up to $7 \mathrm{kHz}$. Birds do not hear ultrasonic sounds. The lower limit of auditory reception is similar in birds and mammals. However, mammals typically are able to detect a broader range of auditory stimuli, with some species hearing sounds up to about $80 \mathrm{kHz}$, depending on the intensity. Efficacy of auditory repellents can increase when the stimulus invokes an antipredator response by enhancing a perceived lethal situation (i.e., presence of a predator).

In addition to auditory stimuli, animals perceive their environment through touch. These tactile senses are most commonly located on the skin and are sensitive to temperature, pressure, and vibration. The trigeminal nerves in the avian bill are also sensitive to oral stimuli, which has been the basis for the development of several 
primary foraging repellents. Tactile repellents typically cause discomfort or pain to target species.

Numerous types of auditory and tactile repellents are available; however, we note that the efficacy of many commercial products has not been rigorously evaluated. Examples of acoustic techniques include broadcasting alarm or distress calls and human-made sounds, or loud sounds from exploders and pyrotechnics. Originally developed for message broadcasting and crowd control, acoustic hailing devices are now being used to deter wildlife at some airports. Examples of tactile repellents include barriers such as spikes and wires to reduce perching and loafing by birds, or chemical applications (e.g., glue) and electric shock that cause discomfort or pain. Although the duration of effectiveness of most auditory and tactile repellents is not known, typical known effectiveness is up to several weeks. Thus, current auditory and tactile repellents are generally considered short-term solutions for deterring wildlife.

The likelihood and magnitude of wildlife responses to auditory and tactile repellents is often influenced by the novelty of the repellent, whether the response is innate or learned, and if the repellent is augmented by additional techniques. Wildlife response to a repellent will generally decrease over time if additional negative reinforcement (e.g., occasional lethal control) does not occur. Even tactile barriers that invoke a painful response can lose efficacy over time if not augmented with occasional lethal control. However, some tactile devices (e.g., spikes and wires) can provide long-term reductions in wildlife use. The efficacy of these and other repellents will be influenced by the attractiveness of the site being protected.

Auditory and tactile repellents should be considered as part of an integrated approach for reducing wildlife risk and complementary to other more permanent techniques (e.g., habitat modification), which can enhance the efficacy of repellents by reducing the initial suitability of the area for wildlife. As with other repellents, animals will often habituate to auditory and some tactile repellents once recognized as a non-lethal threat. Thus, periodically changing the locations of auditory repellents (e.g., propane exploders), as well as altering the frequency and timing of stimuli, can increase their efficacy (Figure 8). Also, the use of auditory repellents that are activated by the animal (e.g., motion-activated propane exploders) can further improve their efficacy over those that are activated at predetermined intervals. We note that the relative efficacy of these repellents will be dependent on species life history. For example, auditory repellents will likely be more effective in dispersing loafing or foraging Canada geese in autumn than during the nesting and brood-rearing seasons.

\section{Chemical Repellents}

Effective use of chemical repellents is dependent upon the sensory capabilities of the target species, context, integration with other methods, and availability of alternative resources. Chemical repellents are classified based on the physiological mode of action and whether avoidance behavior is learned or not. Primary repellents are characterized by unpalatable taste, odor, or irritation and evoke reflexive (i.e., instinctual) withdrawal or escape behavior. In contrast, secondary repellents produce an adverse physiological effect or illness which the animal associates with a sensory cue (e.g., taste, odor, visual cue) and then learns to avoid. Whether using a primary or secondary repellent, optimal use requires that biologists consider 1) how animals learn; 2) the sensory abilities of target animals; 3 ) that repellents are intended to modify behavior; 4) that population turnover can require new training of target animals; and 5) that repellents work best if alternative resources or places are available (i.e., animals with no alternative resources or no place to go might overwhelm the defensive characteristics of any repellent).

Which behaviors define an effective response to a chemical repellent and why? Reflexive withdraw in response to a painful or irritating stimulus (as with a primary repellent) is beneficial to the animal if it prevents further damage or harm. Such withdraw might be due to novelty or immediate pain or discomfort. However, because an animal limits exposure to potentially harmful stimuli, the degree and magnitude of exposure is typically weak, and thus animals do not efficiently form learned associations with primary repellents. As a result, animals exposed to 
primary repellents without further integration of deterrent methods are more likely to revisit sites or sample foods where the stimulus produces a weak or external localized effect.

In contrast, delayed illness associated with a secondary repellent can confer learning. The animal associates the stimulus with sensory cues paired in space and time to form the learned avoidance. For example, anthraquinonebased foraging repellents absorb a range of ultraviolet light such that the pattern of absorbance on treated areas are thought to serve as the stimulus for the subsequent malaise experienced by the bird. However, some associations between the stimulus and the sensory cue are more frequently paired in nature and hence are more readily established. For most mammals, aversions based on flavor cues (taste, odor, irritation) and gastrointestinal illness are readily made. In contrast, birds are less apt to form aversion based on taste, but instead form aversions based on visual cues and gastrointestinal illness.

\section{Population Control}

Management of animals on or near airports via lethal means or reproductive control is generally the last option deployed after all other management actions have been considered or implemented. However, management of a wildlife hazard situation on or near an airport can require killing an individual animal, or reducing a local population of a species by lethal or reproductive means until, if feasible, a long-term, nonlethal solution can be implemented (e.g., erection of deer-proof fence, relocation of nearby gull nesting colony). Also, recurrent lethal control is often necessary as part of an integrated WHMP for an airport.

Biologists should recognize that most wildlife species that use airport environments are protected by some combination of federal (e.g., the Migratory Bird Treaty Act), state, and local laws. Thus, permits are typically required before any action can be taken to capture or kill animals or to control their reproduction. Permits require justification of why the removal is needed, the numbers to be removed by species, and the methods used to remove and dispose of the animals. In addition, management of wildlife populations often generates public interest which airports must acknowledge and address.

In addition to the information necessary to accompany planning for and subsequent monitoring of wildlife population reductions, it is also necessary for airports to justify a lethal control program to regulatory agencies and the public. First, the hazard level and the strike risk posed by the wildlife species must be documented. For example, lethal control may be warranted at a particular airport for species such as Canada geese or white-tailed deer that have a high hazard level (i.e., $\geq 50 \%$ of strikes with aircraft result in damage) and can pose a high risk (i.e., the species has been frequently documented on the airport, is struck frequently, and those strikes pose damage in addition to indirect costs). In contrast, at the same airport it may be inappropriate to request a permit for lethal control of a species that has a relatively low hazard level and is infrequently observed.

Second, biologists should have an understanding of the local and regional population status and dynamics of the problem species. Population data from local surveys, Breeding Bird Surveys, Christmas Bird Counts, and other sources can be integrated with reproductive and survival rates to develop a simple population model for the species of concern. Such a model can serve as a predictive tool that allows assessment of the immediate effect that lethal or reproductive control programs will have on local or regional populations and projection of how populations will respond to management actions.

Third, airports must monitor the population level of the targeted species, as well as the number of strikes and associated damage caused by that species, before and after population management is implemented. In this context, we assume that monitoring comprises of standardized and objective surveys corrected for bias. Monitoring allows for documentation of the effects that management actions have on the population and, most importantly, on the number and frequency of strikes. We note also that prior work in this area suggests these three types of information should be integrated into regional strategic plans that encompass all airports within a specified area, allowing for more efficient permitting, 
implementation, and monitoring of target wildlife species. The emphasis on regional, rather than national, strategies takes into account that problem wildlife species in one area may not necessarily be a problem in another area.

In addition, methods used for wildlife population control should be selected for efficient management of the specific problem and integrated with non-lethal approaches; there is no "general approach" to lethal control. For example, biologists might need to consider a long-term shooting program to defend the air-operations area from consistent over-flights by birds recognized as hazardous to aviation (e.g., the shooting program at John F. Kennedy International Airport that focuses on gull hazards), periodic removal of deer from airport property via sharpshooting, or participation with state and other federal agencies in the capture of molt-stage Canada geese on and near airport properties.

\section{Avian Radar}

Radar (RAdio Detection And Ranging) was developed during the twentieth century for military applications to detect aircraft. During its early use during World War II, it was discovered that radar was able to locate and track birds.

Since that time, biological applications of radar have increased for natural resources monitoring, and a great deal of interest in the use of radar for tracking bird movements (i.e., "avian radar") on a continental basis and at airports to assist aviation safety has emerged. The common use of the technology is to provide personnel at airports or aviation planners more information to assess the possible impacts that birds may have on aircraft operations. A key interest in the technology relies in its ability to identify and track bird targets at ranges that exceed human capabilities, particularly at night.

There are several types of radar that have been used to monitor birds, including marine surveillance radars, tracking radars, weather surveillance radars, and terminal Doppler weather radars. Marine surveillance radars are most commonly modified for use at airports, which often are referred to as "avian radars". These usually have 3-cm

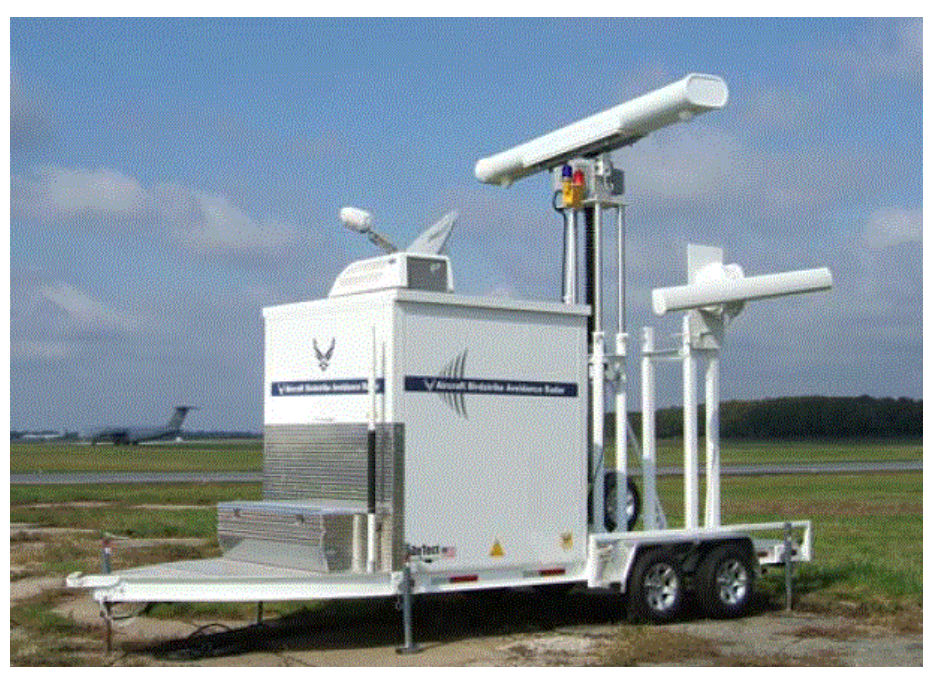

Figure 9. The FAA and several research partners in government (i.e., USDA, Department of Defense) and academia continue to investigate the capabilities of avian radar and its potential efficacy of use at airports.

(X band) or 10-cm (S Band) wavelengths and can have various antenna configurations.

Following the 2009 "Miracle on the Hudson" event when a 155-passenger airliner was forced to make an emergency landing in the Hudson River following a bird strike with a flock of Canada geese, more focus has been placed on the use of avian radar to improve awareness about wildlife movements near airports. In 2011, the FAA issued an Advisory Circular about radar as a basic technology and provided guidance to airports to assist in decision-making if the airport decided to procure an avian radar unit using federal funding assistance.

The FAA and several research partners in government (i.e., USDA, Department of Defense [DoD]) and academia continue to investigate the capabilities of avian radar and its potential use at airports (Figure 9). Several studies examining what radar discriminates and tracks, combined with how to use the data, have suggested that existing systems (small mobile marine-style avian radars) are not able to conclusively identify birds to the species level or discriminate size classes on a reliable basis. Additional problems can lead to inadequate or under-reported birds and bird movements. However, current technology can be adequate to provide information on local and regional 
bird movements that is useful to airports. This may be particularly helpful given the realization that an increasing trend in damaging strikes occur away from the airport environment (i.e., at higher altitudes).

Currently, a major deficiency in the use of avian radar at airports relates to a lack of universally-accepted procedures for its use (i.e., concept of operations, or "conops") and how to integrate the technology into the existing operations paradigm. Some airports, particularly DoD installations which have more flexibility in flight operations than do commercial airports, have successfully developed con-ops procedures, and these examples have resulted in successful mitigation of bird and habitat hazards at airports. However, until a broad-based and acceptable conops is developed for all airports, the deployment of avian radar at airports will be constrained.

\section{Airport Assistance}

In the U.S., certificated and non-certificated airports are required by federal regulation to mitigate safety issues associated with wildlife hazards if the airport receives federal funding to support operating activities. These airports often require the assistance of natural resource professionals to assess and recommend strategies to reduce wildlife hazards. Given the long-term recognition and function of federal agencies in assisting the public with safety and wildlife damage management concerns, a series of programs exist in the DoD, FAA, and USDA to assist civil and military airports with wildlife hazards. Specifically, the USDA Wildlife Services program and elements of the program's predecessors have provided assistance to airports since the mid-1950s. Additionally, wildlife biologists in other agencies and professionals in other disciplines are involved in the management of wildlife at airports, mainly owing to the different regulations involved at the state or federal level. Also, the private sector is increasingly providing professional personnel that possess the required training and experience to assist airports.
When airports require assistance assessing wildlife concerns, various types of agreements or contracts are used to facilitate the funding process. The FAA provides funding assistance to certificated airports from the Airport Improvement Program fund to conduct WHAs. Some larger airports in the U.S. have expanded their own staff to include professionally-trained wildlife biologists to address wildlife hazards. The FAA requires that WHAs and certain other activities at airports are conducted by wildlife biologists who receive recurrent training. In the U.S., this has become somewhat of a best management practice, and wildlife biologists providing assistance at military airports are similarly trained.

Many agencies and organizations are engaged at state and federal levels in the management of wildlife at airports. Starting in the late 1980s, a series of agreements and understandings were initiated at the federal level to increase interaction and awareness between the several agencies actively dealing with wildlife issues at airports.

These relationships have provided the foundation for expanded research efforts and cooperation, particularly among the FAA, DoD, and USDA. Other organizations centered at the state aviation level (e.g., National Association of State Aviation Officials) also are engaged with their federal partners. The U.S., in accordance with existing international guidance, also has a bird strike committee comprised of aviation, government, and other concerned parties that provides a forum for the exchange of ideas and best management practices. In 2012, Bird Strike Committee USA and the FAA signed a memorandum of understanding to further strengthen communication and awareness of this issue for the benefit of airports and the flying public. 


\section{Conclusion}

Effective management of wildlife to reduce strikes, like all types of wildlife damage management, is based on principles from wildlife ecology, physiology, and behavior. Airport biologists should consider how these disciplines interact in the airport context, particularly with an understanding of regulatory guidance, non-wildlife related airport safety priorities, and strike data. This "marriage" of wildlife ecology with aspects of airport operations will aid in discerning how and why animals respond to various mitigation methods (at both the individual and population levels), why and under what conditions some management tools and techniques work better than others, and allow airport biologists to more intelligently direct management efforts. 


\section{Acknowledgements}

Figure 1. Photo by USDA-APHIS-WS

Figure 2. Photo by USDA-APHIS-WS

Figure 3. Photo by USDA-APHIS-WS

Figure 4. Photo by Christopher Loftis, USDA-APHIS-WS

Figure 5. Photo by Kendra Cross, USDA-APHIS-WS

Figure 6 . Photos by USDA-APHIS-WS

Figure 7. Photo by USDA-APHIS-WS

Figure 8 . Photo by USDA-APHIS-WS

Figure 9. Photo by USDA-APHIS-WS

Management of wildlife hazards to aviation is a multi-faceted challenge involving basic and applied research, as well as long-term evaluation and development of management methods. In writing this publication, we relied heavily on authors who published previously in these areas. In particular, this publication draws from material presented in the book "Wildlife in airport environments: preventing animal-aircraft collisions through science-based management," published by Johns Hopkins University Press in 2013. We thank M. Avery, K. Biondi, J. Cepek, L. Clark, T. Conkling, S. Craven, P. Curtis, R. Dolbeer, D. Felstul, E. Fernández-Juricic, A. Franklin, S. Gauthreaux, M. Lavelle, J. Martin, R. Mihalco, P. Schmidt, T. Seamans, K. VerCauteren, and B. Washburn for contributing to that book. We also thank R. Dolbeer, T. Seamans, and B. Washburn for reviewing a draft of this publication and E. Poggiali for administrative support. Much of our research on wildlife hazards to aviation is funded by the Federal Aviation Administration (FAA). However, opinions expressed in this publication do not necessarily reflect current FAA policy decisions governing the control of wildlife on or near airports.

\section{Glossary}

Advisory Circular: Non-regulatory guidance document published by the U.S. Federal Aviation Administration (FAA) that covers a specific subject area under airport operations and management.

Air Operations Area/Aerodrome: Area designated for aircraft gate operations, taxing, takeoff and landings.

Certified Airport: Airports approved by the FAA for regularly scheduled (9 seats) or unscheduled (30 seats) passenger traffic.

Primary Repellent: Characterized by unpalatable taste, odor, or irritation and evokes reflexive (i.e., instinctual) withdrawal or escape behavior.

Secondary Repellent: Produces an adverse physiological effect or illness which the animal associates with a sensory cue (e.g., taste, odor, visual) and then learns to avoid it.
Wildlife Hazards Assessment: One-year assessment of wildlife use of an airport and associated habitats/features that serve as wildlife attractants conducted as directed by the FAA.

Wildlife Habitat Management Plan: An ongoing management action to reduce wildlife strike hazards and, subsequently, strike risk, that involves monitoring of wildlife use of the airport, active harassment of hazardous wildlife, and adaptive management to curb wildlife use.

Wildlife Strike Hazard: Habitat, structure, or practice that enhances use by wildlife.

Wildlife Strike Risk: Realized probability of a damaging strike with a given species

\section{Key Words}

Aircraft, airport, antipredator behavior, aviation, bird strike, Branta canadensis, Canada goose, collision, fencing, habitat modification, lethal control, Odocoileus virginianus, pyrotechnics, repellent, sensory ecology, white-tailed deer, wildlife strike 


\section{Disclaimer}

Wildlife can threaten the health and safety of you and others in the area. Use of damage prevention and control methods also may pose risks to humans, pets, livestock, other non-target animals, and the environment. Be aware of the risks and take steps to reduce or eliminate those risks.

Some methods mentioned in this document may not be legal, permitted, or appropriate in your area. Read and follow all pesticide label recommendations and local requirements. Check with personnel from your state wildlife agency and local officials to determine if methods are acceptable and allowed.

Mention of any products, trademarks, or brand names does not constitute endorsement, nor does omission constitute criticism.

\section{Citation}

DeVault, T.L., B.F. Blackwell, J.L. Belant, and M.J. Begier. 2017. Wildlife at Airports. Wildlife Damage Management Technical Series. USDA, APHIS, WS National Wildlife Research Center. Fort Collins, Colorado. 19p.

\section{Resources}

Belant, J. L., and J. A. Martin. 2011. Bird harassment, repellent, and deterrent techniques for use on and near airports. Airport Cooperative Research Program Synthesis 23, Transportation Research Board of The National Academies. Washington, DC.

Biondi, K. M., J. L. Belant, J. A. Martin, T. L. DeVault, and G. Wang. 2011. White-tailed deer incidents with U.S. civil aircraft. Wildlife Society Bulletin 35:303-309.

Bird Strike Committee USA (http://www.birdstrike.org/)

Blackwell, B. F., T. L. DeVault, E. Fernández-Juricic, and R. A. Dolbeer. 2009. Wildlife collisions with aircraft: a missing component of land-use planning for airports. Landscape and Urban Planning 93:1-9.

Blackwell, B. F., L. M. Schafer, D. A. Helon, and M. A. Linnell. 2008. Bird use of stormwater-management ponds: decreasing avian attractants on airports. Landscape and Urban Planning 86:162-170.

Blackwell, B. F., T. W. Seamans, K. Linnell, L. Kutsch-Bach Brohl, and T. L. DeVault. 2016. Effects of visual obstruction, prey resources, and satiety on bird use of simulated airport grasslands. Applied Animal Behaviour Science 185:113-120.

Blackwell, B. F., T. W. Seamans, P. M. Schmidt, T. L. DeVault, J. L. Belant, M. J. Whittingham, J. A. Martin, and E. FernándezJuricic. 2013. A framework for managing airport grasslands and birds amidst conflicting priorities. Ibis 155:199-203.

Cleary, E. C., and R. A. Dolbeer. 2005. Wildlife hazard management at airports, second edition. U.S. Department of Transportation, Federal Aviation Administration, Office of Airport Safety and Standards, Airport Safety and Compliance Branch, Washington, DC, USA. 
DeVault, T. L., J. L. Belant, B. F. Blackwell, J. A. Martin, J. A. Schmidt, L. W. Burger, Jr., and J. W. Patterson, Jr. 2012. Airports offer unrealized potential for alternative energy production. Environmental Management 49:517-522.

DeVault, T. L., J. L. Belant, B. F. Blackwell, and T. W. Seamans. 2011. Interspecific variation in wildlife hazards to aircraft: implications for airport wildlife management. Wildlife Society Bulletin 35:394-402.

DeVault, T. L., B. F. Blackwell, and J. L. Belant, editors. 2013. Wildlife in airport environments: preventing animal-aircraft collisions through science-based management. Johns Hopkins University Press, Baltimore, MD, USA, 181 pp.

DeVault, T. L., T. W. Seamans, J. A. Schmidt, J. L. Belant, B. F. Blackwell, N. Mooers, L. A. Tyson, and L. Van Pelt. 2014. Bird use of solar photovoltaic installations at US airports: implications for aviation safety. Landscape and Urban Planning 122:122128.

Dolbeer, R. A. 2006. Height distribution of birds recorded by collisions with civil aircraft. Journal of Wildlife Management 70:1345-1350.

Dolbeer, R. A., M. J. Begier, and S. E. Wright. 2008. Animal ambush: the challenge of managing wildlife hazards at general aviation airports. Corporate Aviation Safety Seminar 53:1-12.

Dolbeer, R. A., J. L. Belant, and J. Sillings. 1993. Shooting gulls reduces strikes with aircraft at John F. Kennedy International Airport. Wildlife Society Bulletin 21:442-450.

Dolbeer, R. A., J.R. Weller, A.L. Anderson and M. J. Begier. 2016. Wildlife Strikes to Civil Aircraft in the United States, 19902015. U.S. Department of Transportation, Federal Aviation Administration, Office of Airport Safety and Standards, Serial Report No. 22, Washington, DC, USA.

Environmental Protection Agency-Water Pollution Prevention and control, Low-Impact Development (LID) (http:// water.epa.gov/polwaste/green/ ).

Federal Aviation Administration. 2007. Hazardous wildlife attractants on or near airports. Advisory Circular 150/5200-33B. U.S. Department of Transportation, Washington, D.C., USA.

Federal Aviation Administration. 2010. Airport avian radar systems. Advisory Circular 150/5220-25. U.S. Department of Transportation, Washington, D.C., USA.

Federal Aviation Administration Wildlife Hazard Mitigation Program (http://www.faa.gov/airports/airport safety/wildlife/).

Gerringer, M. B., S. L. Lima, and T. L. DeVault. 2016. Evaluation of an avian radar system in a midwestern landscape. Wildlife Society Bulletin 40:150-159.

Green Infrastructure (http://water.epa.gov/infrastructure/greeninfrastructure/index.cfm).

Internet Center for Wildlife Damage Management (http://icwdm.org).

International Bird Strike Committee (http://www.int-birdstrike.org).

International Civil Aviation Organization (http://www.icao.int).

Mackinnon, B. 2004. Sharing the skies: an aviation industry guide to the management of wildlife hazards. TP 13549.

Transport Canada, Aviation Publishing Division, Ottawa, Ontario, Canada. 
National Wildlife Control Training Program (http://wildlifecontroltraining.com).

Rutledge, M. E., C. E. Moorman, B. E. Washburn, and C. S. DePerno. 2015. Analyzing resident Canada goose movements to reduce the risk of goose-aircraft collisions at suburban airports. Journal of Wildlife Management 79:1185-1191.

Schmidt, J. A., B. E. Washburn, T. L. DeVault, T. W. Seamans, and P. M. Schmidt. 2013. Do native warm-season grasslands near airports increase bird strike hazards? American Midland Naturalist 170:144-157.

Schwarz, K. B., J. L. Belant, J. A. Martin, T. L. DeVault, and G. Wang. 2014. Behavioral traits and airport type affect mammal incidents with U.S. civil aircraft. Environmental Management 54:908-918.

Washburn, B. E., P. J. Cisar, and T. L. DeVault. 2013. Wildlife strikes to civil helicopters in the US, 1990-2011. Transportation Research Part D 24:83-88.

Washburn, B. E., and T. W. Seamans. 2012. Foraging preferences of Canada geese among turfgrasses: implications for reducing human-goose conflicts. Journal of Wildlife Management 76:600-607.

USDA Wildlife Services research and management regarding wildlife at airports (http://www.aphis.usda.gov/wildlife damage/ airline safety/airport hazards.shtml). 